\title{
BRASILEIRO TRADUTOR E/OU TRAIDOR: FREI JOSÉ MARIANO DA CONCEIÇÃO VELOSO
}

\author{
Alessandra Ramos de Oliveira Harden \\ Universidade de Brasília/University College Dublin \\ oliveira.ales@gmail.com
}

\begin{abstract}
Resumo: Este artigo aborda um momento específico da história da tradução em língua portuguesa, o movimento de tradução de textos científicos e didáticos ocorrido no final do século XVIII em Portugal, em que um número expressivo de brasileiros esteve envolvido. O foco é o trabalho do frei mineiro José Mariano da Conceição Veloso, figura modernamente associada à história das ciências e à história do livro em Portugal e no Brasil. Frei Veloso foi tradutor, editor e coordenador do trabalho de outros tradutores de textos pragmáticos em Lisboa. Sua atuação na incipiente indústria editorial na então metrópole estava ligada a elementos específicos da Ilustração Portuguesa, particularmente no que se refere à divulgação de conhecimento científico aplicável ao progresso do reino de Portugal. Traços do envolvimento do Frei Veloso com as políticas portuguesas são encontrados nos prefácios que anexou a suas traduções, e esses sinais permitem incluí-lo em um sistema de patronagem que definiu os rumos de sua atividade editorial. Curiosamente, embora ligado ao regime monárquico autoritário português, o trabalho de Frei Veloso levou, ainda que de forma indireta, a avanços históricos inesperados, como o desenvolvimento do hábito de leitura e de técnicas de impressão.
\end{abstract}

Palavras-chave: história da tradução, século XVIII, Portugal, Brasil, Frei José Mariano da Conceição Veloso, patronagem.

\footnotetext{
Abstract: This article is concerned with a specific phenomenon of the history of translation into Portuguese, the boom of translation of scientific and didactic texts in the turn of the $18^{\text {th }}$ century in Portugal, in which a considerable number of Brazilians were involved. We focus the work of Friar José Mariano da Conceição Veloso, who has lately been referred to as a key figure in the history of sciences and books publishing in Portugal
} 
and Brazil. Friar Veloso was translator, editor, and translation coordinator in charge of the work of translators concerned with pragmatic texts in Lisbon. Veloso's involvement with the still incipient editorial industry in Portugal was linked to Portuguese Enlightenment, especially the dissemination of scientific knowledge that could be applied to the progress of the Portuguese kingdom. Clues of Friar Veloso's close connection with the Portuguese official policies are found in the prefaces he wrote for his translations, and they are enough to include him withim a patronage system that defined the direction his editorial activities would take. Curiously, despite these ties to the authoritarian Portuguese monarchical regime, Friar Veloso's work led to unexpected historical developments, such as the growth of the reading public and the improvement of printing techniques.

Keywords: history of translation, $18^{\text {th }}$ century, Portugal, Brazil, Friar José Mariano da Conceição Veloso, patronage.

Nos anos que precederam a transferência da corte portuguesa para o Rio de Janeiro, concretizada em 1808, Portugal vivenciou um boom de publicações na área das ciências, um fenômeno que pode ser entendido como parte da Ilustração Portuguesa. O Iluminismo havia criado um entusiasmo científico que varreu a Europa e que estava intimamente ligado a novas formas de ver o mundo e os fenômenos naturais, às relações entre esse mundo e o ser humano, e, consequentemente, a uma nova atitude frente à Igreja e a outras fontes tradicionais de autoridade.

Em Portugal, no entanto, o entusiasmo iluminista encontrou obstáculos, impostos tanto pela Igreja quanto pelo Estado, e a censura foi um dos instrumentos usados para conter o avanço das ideias dos perigosos filósofos. Os censores controlavam com mão de ferro tudo o que os súditos portugueses (inclusive os habitantes das colônias) liam, e, embora haja registros de muitos casos de contrabando de livros proibidos, a tradução, a publicação e a leitura de vários autores importantes do Iluminismo eram objeto de vigilância constante e até de proibição legal (cf. Martino; Sapaterra, 2006).

Um aspecto do Iluminismo, entretanto, caracterizou a Ilustração Portuguesa: a crença nas ciências aplicadas à promoção do progresso e da riqueza nacional. Assim, embora o acesso aos livros 
de muitos autores iluministas mais ligados a questões políticas e filosóficas fosse proibido, o mesmo não ocorreu com as ciências naturais. A partir de 1780, as publicações em matérias como química, física, matemática, agricultura e medicina cresceram muito em Portugal, com o aparecimento de livros e folhetos de cunho didático, cujo objetivo era a divulgação de conhecimento prático que pudesse ser útil ao reino. Lia Wyler refere-se a esse período com as seguintes palavras:

\begin{abstract}
Em fins do século XVII iniciou-se em Portugal um movimento idealizado e executado por brasileiros visando diretamente ao Brasil. Refletia a ideologia do Século das Luzes, responsável pela priorização do ensino das ciências na Universidade de Coimbra, pelas expedições científicas do Império Português, a concessão de bolsas de estudo em grandes centros europeus, a divulgação das ideias dos enciclopedistas e a fundação da Academia Real de Ciências em Lisboa (Wyler, 2003, p. 73).
\end{abstract}

No âmbito desse projeto progressista, a tradução desempenhou papel essencial. Vários tratados e descrições escritos em língua estrangeira, especialmente em francês e inglês (Faria, 1999, p. 1167), foram vertidos para o português com a bênção dos poderosos, inclusive sob encomenda do próprio Príncipe Regente D. João. A noção subjacente a esse boom de traduções (quase) científicas estava associada ao aspecto utilitário da ciência, em conformidade com as ideias dos fisiocratas franceses. Tratava-se da difusão das "luzes das ciências, sobretudo no domínio da agricultura, adaptando a ideia fisiocrática nas colônias" (Curto, 1999, p. 48), para devolver a Portugal seu lugar entre as grandes nações.

Nesse sentido, a produção de obras em áreas das ciências aplicadas foi uma das estratégias utilizadas para trazer o avanço para o reino, como parte de uma política baseada no princípio de que à metrópole cabia o papel de prover as artes e as letras, e às colônias, a função de abastecer o reino com produtos agrícolas que pudessem 
competir com os produtos comercializados por outras potências coloniais, como Inglaterra e Espanha. Coube ao poderoso Dom Rodrigo de Souza Coutinho, ministro da marinha e do ultramar, colocar em prática essa política, articulando os "interesses metropolitanos com os das elites coloniais, incorporando membros da elite letrada brasileira em um projeto político conjunto de Império transatlântico, no qual a colônia teria papel crucial e ativo na superação do atraso português" (Wegner, 2004, p. 132).

O homem das letras escolhido por Dom Coutinho para coordenar as atividades do Estado no seu papel pedagógico (no sentido de levar conhecimento aos produtores que dele precisavam) foi o franciscano José Mariano da Conceição Veloso ${ }^{1}$, botânico brasileiro autodidata, já respeitado em Lisboa e famoso por seu amor pelos livros e pelo conhecimento. Ele já havia tomado parte nas chamadas viagens filosóficas (para exploração e descrição do território e espécies brasileiras) e foi, por algum tempo, membro da Academia de Ciência de Lisboa. Era um homem com interesses diversos, que iam das ciências biológicas às línguas estrangeiras e clássicas, da literatura à filosofia.

O ponto alto da carreira de Veloso deu-se com a criação da Officina Litteraria Casa do Arco do Cego, em 1799, por ordem do ministro Dom Coutinho. Embora não se tenha encontrado nenhum documento oficial que determinasse sua criação, como um decreto real ou alvará, acredita-se que a Arco do Cego tenha sido fundada com o objetivo específico de promover e desenvolver as artes, a indústria e a agricultura em Portugal e no Brasil. A administração da nova tipografia/editora ficou a cargo do Frei Veloso, nomeado por Coutinho, e a Casa do Arco do Cego transformou-se no principal estabelecimento de publicação de livros científicos e didáticos na época, apesar da vida curtíssima que teve. Em funcionamento entre 1799 e 1801, publicou mais de 80 obras, entre traduções e textos originalmente escritos em português e latim.

As traduções de Veloso, porém, já ocorriam desde 1796, quando ele iniciou, em Lisboa, a publicação do periódico Palladio Portuguez e Clarim de Palla, "no qual difundia as novidades coloniais 
e traduzia textos estrangeiros referidos à vida rural" (Priore; Venâncio, 2006, p. 104). Entre 1797 e 1805, traduziu pelo menos 20 obras (traduções assinadas ou creditadas a ele) e supervisionou a tradução de cerca de outras 30, na área das ciências ou tecnologia e a partir de línguas diferentes (espanhol, francês, italiano e inglês). Seu interesse pelas letras também se refletem na elaboração do Diccionario Portuguez e Brasiliano, em 1795, referente à língua geral do Brasil.

Sua atuação frente à Arco do Cego, como administrador e editor, coincidiu com uma fase muito produtiva da sua vida como tradutor de textos de temas variados. Alguns dos títulos de obras que traduziu dão ideia da diversidade de seus interesses e do tipo de texto incluído nos seus planos de divulgação científica:

Discurso Prático Sobre a Cultura, Maceração e Preparação do Cânamo, lido e aprovado pela Real Sociedade Agraria de Turim, na sessão de 8 de Maio de 1795 e dedicado à mesma Sociedade por seu autor. Lisboa: Off. de Simão Thaddeo Ferreira, 1799.

1. Memória Sobre a Moagem dos Graons, e Outros Objetos Relativos: por Mr. João Luiz-Muret. Jean Louis Muret; Lisboa: Typographia Chalcographica, e Litteraria do Arco do Cego, 1800.

2. Helmintologia Portuguesa, em que se descrevem alguns generos das duas primeiras ordens (...) segundo o systema do cavalheiro Carlos Linnee. Jacques Barbut; Lisboa: Off. João Procópio Correa da Silva, 1799.

3 Memória Sobre a Cultura da Urumbeba, e Sobre a Criação da Cochonilha, extrahida por M. Bertholet das observações feitas em Guaxaca por M. Thiery de Menonville; e copiada do V. Tomo dos Annaes de Chymica. Claude Louis Berthollet; Lisboa: Off. de Simão Thaddeo Ferreira, 1799. 
4. A Sciencia das Sombras Relativas ao Desenho; obra necessaria a todos, que querem desenhar architectura civil, e militar, ou que se destinão a pintura, etc. na qual se acharão regras demonstradas para conhecer a especie, a forma, a longitude, e a largura das Sombras, que os differentes corpos fazem, e produzem, assim sobre superficies horizontaes, verticaes, ou inclinadas, como sobre as superficies verticaes, planas, convexas, ou concavas. Por M. Dupain. Lisboa: Off. João Procopio Correa da Silva, 1799.

5. Alographia dos Alkalis Fixos, vegetal ou potassa, mineral ou soda e dos seus nitratos, segundo as melhores memorias estrangeiras, que se tem escripto a este assumpto. Lisboa: Off. de Simão Thaddeo Ferreira, 1798.

6. Memoria sobre a Cultura, e Preparação do Girofeiro Aromatico vulgo cravo da Índia nas ilhas de Bourbon e Cayena, estrahida dos Annaes de Chymica (e outras). Lisboa: Off. de João Procópio Correa da Silva, 1798.

Pode-se observar, com esses poucos exemplos, o cuidado com a escolha de textos acerca de assuntos de relevância estratégica e econômica para o reino português e ligados a fontes e autores respeitados, como indica a menção dos nomes de Lineu (3) e dos Annaes de Chymica (7) (Annales de Chimie - publicação francesa muito conhecida, criada por cientistas como Antoine Lavoisier). Outro elemento relevante no trabalho de Veloso é o contato que manteve com várias tipografias lisboetas para a publicação de suas traduções (e de outros tradutores que atuavam na Arco do Cego) ${ }^{2}$. $\mathrm{O}$ recurso ao trabalho de tipógrafos e oficinas diferentes foi uma estratégia que possiblitou a produção de um grande número de obras em quantidades consideráveis. Muito provavelmente, tratou-se de um elemento essencial dentro do projeto editorial de Veloso, por demais ambicioso para ser concretizado somente nas instalações da Arco do Cego (Domingos, 1999, p. 96). 
Foi graças a essa estratégia que Veloso conseguiu publicar o notável $O$ Fazendeiro do Brasil - O Cultivador, seu maior feito no que se refere à tradução. A obra completa é formada por 10 volumes, em que textos de diversos autores europeus e norte-americanos são compilados e traduzidos para o português. A publicação ocorreu em fases, entre 1798 e 1806. Os tópicos incluídos nessa obra definem a linha temática do trabalho de Veloso e da Arco do Cego, ou seja, textos de ciências aplicadas à agricultura e dirigidos especialmente ao Brasil (Faria, 1999, p. 114). Também podem ser vistos como tópicos ilustrativos do boom de tradução pragmática português como um todo, já que se referiam a áreas de relevância econômica para o reino: cana-de-açúcar, café, cacau, especiarias, tinturaria e cordoaria.

O prefácio do primeiro tomo do $O$ Fazendeiro do Brasil - o Cultivador, sobre cana-de-açúcar, é citado como evidência de que Coutinho tivesse de fato ordenado ao Frei que traduzisse e publicasse livros estrangeiros "úteis aos que por eles se interessassem, especialmente os fazendeiros do Reino, para que expandissem seus horizontes de conhecimento e se familiarizassem com novos produtos e técnicas (...) especialmente para o deslumbrante Novo Mundo, o Brazil” (Nunes; Brigola, 1999, p. 63). Nesse prefácio, em que não há há detalhes sobre a data exata em que Veloso teria recebido essa incumbência, sobre quem lhe teria atribuído tal tarefa nem sobre os aspectos formais que envolveram essa ordem, Veloso declara ter sido

incumbido, a saber: de ajuntar e trasladar em português todas as memórias estrangeiras que fossem convenientes aos Estabelecimentos do Brasil, para melhoramento da sua economia rural e das fábricas que dela dependem, pelas quais ajudadas houvessem de sair do atraso e atonia em que atualmente estão e se pusessem ao nível com os das nações nossas vizinhas e rivais no mesmo continente, assim na quantidade como na qualidade dos seus generos e produções (Vellozo, 1798, p. i). 
Frei Veloso pode ser considerado o mais importante dentre os tradutores brasileiros envolvidos no movimento português de tradução de obras "convenientes" e "úteis", por motivos que são diversos mas se complementam. Além de seus muitos talentos, que empregou na tradução, edição, compilação e publicação de obras sobre temas científicos e técnicos, Veloso agregou a sua volta um grupo que incluía personagens que se tornariam grandes nomes da história brasileira, como os irmãos Antonio Carlos e Martim Francisco Ribeiro de Andrade, Manoel Jacinto Nogueira da Gama e Hypolito José Pereira da Costa ${ }^{3}$. Ele supervisionou esses tradutores na Arco do Cego e possivelmente influenciou as estratégias tradutórias por eles utilizadas. Veloso já foi descrito como um frei comprometido em termos pedagógicos com a promoção das ideias iluministas para a agricultura (Nunes; Brigola, 1999, p. 68), e a afirmação que fez no prefácio de uma de suas traduções, "Sem livros não há instrução" (Vellozo, 1800, p. iv), parece tê-lo guiado por toda vida. Esses fatos certamente são suficientes para que ele e sua obra sejam considerados dignos da atenção dos estudos de tradução no Brasil e em Portugal.

No entanto, suas atividades como tradutor/editor não podem ser desassociadas de outros de seus feitos, entre os quais merecem nota os seguintes:

- $\quad$ Examinar, descrever e coletar espécies vegetais brasileiras, como naturalista, botânico e museólogo.

- $\quad$ Ter enorme influência na história do livro e na história da arte em Portugal e Brasil, pois organizou, na Arco do Cego, curso de gravura considerado o mais importante do gênero em Portugal, com aulas moldadas "em bases modernas" e frequentadas "por numerosos alunos" (Gama, 1967, p. 51).

- Contribuir para a utilização do português como língua de expressão científica, em substituição ao latim, o que 
ajudou a valorização da língua nacional em oposição ao uso de línguas que dificultavam o acesso ao saber.

- Ajudar a concretizar os ideais utilitários do Iluminismo, em termos de divulgação de conhecimento científico e pragmático, especialmente com o uso de gravuras para facilitar a compreensão do texto (cf. Wegner, 2004).

- Ser o braço executor de uma política portuguesa cujo objetivo era fazer do Brasil uma fonte produtiva e moderna de produtos agrícolas, enquanto a metrópole mantinha sua posição como referência cultural e intelectual (cf. Curto, 1999).

- Lançar um marco sem precedentes na história da tradução para a língua portuguesa, tanto pelo número de traduções que realizou, editou e/ou publicou quanto pela natureza pioneira do projeto de tradução que supervisionou na Arco do Cego (Wyler, 2003, p. 73-6).

Diante de tudo isso, a pesquisa em história da tradução em língua portuguesa tem no trabalho de Veloso uma fonte muito rica de informação acerca do contexto de produção das traduções feitas entre os séculos XVIII e XIX. Nesse sentido, a análise dos prefácios escritos por ele e anexados a suas traduções podem ser de grande utilidade.

Os exemplos abaixo são representativos da voz de Veloso em seus prefácios e do discurso mediante o qual ele se apresenta a seus leitores. São trechos retirados dos prefácios dos livros Helminthologia Portuguesa e O Fazendeiro do Brazil - Cultivador (Tomo I, Parte II) (com as grafias utilizadas nos originais mantidas). Helminthologia Portuguesa (Vellozo, 1799a, Prefácio, s.p)

Trecho 1: “... V. A. R. [Vossa Alteza Ral] (...) possuindo o seu Augusto, e terno coração, em grão heroico, as mesmas virtudes, e piedosos sentimentos daquelle antigo Sobera- 
no [o Sábio e Santo Rei David], com as mesmas luzes de sã Filosofia ...".

Trecho 2: “... a grandeza da protecção que V. A. R. concede a esta qualidade de estudos (...) a mesma paixão que caracterizou aos maiores Soberanos da Europa...".

Trecho 3: "[Os filósofos seguem] a voz do seu Supremo Imperante (...) Assim gozará V. A. R. de hum attributo, só proprio dos Supremos Imperantes, qual o de criar genios".

Trecho 4: "Para tudo conto com a incomensuravel grandeza da Alma de V. A. R. em cuja presença prostrado offerece este trabalho, e toda a sua continuação O mais humilde entre os Vassalos".

O Fazendeiro do Brazil - O Cultivador, Tomo I, Parte II, (Vellozo, 1799b, Prefácio)

Trecho 1: “A Segunda Parte do primeiro Tomo (...) sóbe á Augusta presença de VOSSA ALTEZA REAL a buscar a Regia approvação..." (p. iii).

Trecho 2: "Bastará finalmente ter sido [o açucar] da Invenção e Protecção do Senhor Infante D. Henrique, de immortal Memoria, que VOSSA ALTEZA REAL conta entre os seus Augustos Ascendentes, e nos entre os nossos virtuosos Principes..." (p. vii).

Trecho 2: "Salve Deos a Augusta Pessoa de VOSSA ALTEZA REAL, e toda a Real Familia, consultando favoravelmente á perennidade de seus bellos dias, da sua grande gloria, e do nosso desejo e necessidade. Assim o pede De VOSSA ALTEZA REAL O mais obediente Vassalo" (p. vii). 
Embora breves, os trechos acima trazem elementos que caracterizam os prefácios de Veloso e também os de outros tradutores da época. Esses prefácios de traduções são na verdade dedicatórias, de natureza epistolar. São textos que dedicam a obra (tanto a tradução quanto a própria publicação) ao representante da família real que dirigia Portugal à época, o Príncipe Regente Dom João, e a ele se dirigem de forma direta. Têm o vocativo "Senhor" como saudação inicial e a expressão "de seu mais obediente vassalo" (ou frase similar) como fórmula de fechamento.

A linguagem utilizada, como pode ser observado, é exageradamente respeitosa e há muitos adjetivos e elogios referentes à atuação ou às "luzes" do Príncipe e de seus familiares. São feitas referências ao amor e respeito do tradutor ao Príncipe, como a declaração de que o tradutor, "o mais humilde entre os Vassalos", "prostrado offerece este trabalho" (Vellozo, 1799a, Prefácio, s.p.). Esse tom reverencial é típico do gênero textual dedicatória epistolar, também identificável pelo uso de linguagem excessivamente laudatória.

Essas características textuais indicam que os prefácios de Veloso foram produzidos no âmbito de uma relação de patronagem com o governo português. Como ensina Chartier (1996, p. 209), em um sistema de patronagem, cientistas, filósofos e poetas tentavam, pela força das palavras, atrair os favores de um aristocrata que pudesse financiar suas obras, em uma época em que o mercado ainda incipiente não garantia a esses estudiosos e escritores rendimentos suficientes. No caso de Veloso, os favores recebidos eram muitos, assim como eram muitos os elogios ao Príncipe feitos em suas dedicatórias.

Lefevere afirma que a patronagem consiste de três elementos básicos: o fator ideológico, o fator econômico e o fator ligado a status (1992, p. 16). Esses elementos são identificáveis na vida de Veloso. Suas conexões com a realeza portuguesa, e especialmente com o ministro Dom Coutinho, foram decisivas para o sucesso de seu empreendimento editorial. O frei brasileiro contava com a proteção e com o auxílio de Coutinho, mesmo antes de se tornar 
administrador da Arco do Cego. Na verdade, sua posição como diretor da Arco do Cego e a posterior nomeação como diretor literário da Imprensão Régia, em 1801, tiveram duplo efeito: garantiram-lhe posição entre os membros da elite educada de Lisboa e renderam-lhe uma pensão que durou, aparentemente, até o fim de seus dias (Nunes; Brigola, 1999, p. 69-70). Também é significativo que as despesas da Casa Literária do Arco do Cego eram pagas pelo gabinete de Coutinho (Domingos, 1999), o que obviamente incluía o pagamento das traduções feitas, e que a Veloso tenha sido prometida a publicação de sua obra-prima Flora Fluminense às custas do erário português (uma promessa feita por decreto real e nunca cumprida pelos portugueses, pois a publicação só ocorreu em 1825, pela Typografia Nacional, no Rio de Janeiro, mesmo assim, de forma incompleta). De fato, em artigo sobre as receitas e despesas da Arco do Cego, Domingos afirma que

[n]uma apreciação global de todas as despesas efectuadas ao longo dos 28 meses de vigência legal do estabelecimento, induz-se que a fonte de financiamento foi quase sempre a mesma: verbas diretamente atribuídas para a execução dos 'trabalhos literários' no seu todo, quer dizer, pagas por conta do 'rol' de cada mês. A Secretaria da Marinha, como se afirmou, tutelava a iniciativa (...) Na dependência direta de D. Rodrigo de Sousa Coutinho, até Janeiro de 1801, não se verificam problemas de monta (...). (1999, p. 101).

Esses fatos seguramente podem ser reconhecidos como os elementos econômicos e de status a que Lefevere se refere.

Quanto ao componente ideológico, seu interesse no progresso e na educação, aparentemente legítimo, em princípio explica o relacionamento entre Veloso e Coutinho. Ambos compartilhavam as mesmas ideias no que se refere à divulgação e à aplicação do conhecimento científico então disponível e queriam um Portugal mais forte e mais moderno, capaz de competir com as outras nações eu- 
ropeias, especialmente França, Inglaterra e a sempre concorrente Espanha. A fundação da Casa do Arco do Cego foi uma tentativa de se chegar a esse progresso, por meio da produção de livros nas áreas relevantes, o que significava também as traduções de obras estrangeiras. Tanto é assim que o mesmo decreto que criou a Impressão Régia, em 1801, obrigou tal instituição a dar continuidade aos trabalhos já iniciados na Arco do Cego. A Impressão Régia incorporou, portanto, essa última, inclusive recebendo seu administrador em seus quadros, agora como um de seus diretores literários, agentes "encarregados da traducção das Obras, que hajão de publicar-se". O decreto é claro quanto ao tipo de publicação a ser feita pela Impressão Régia, que deverá:

continuar a impressão dos Livros, e Obras, de que se achava encarregada a Casa Literaria do Arco do Cego, e particularmente das Obras Botanicas de Fr. José Mariano da Conceição Veloso, assim como fará concluir todas as Obras, que se achão alli principiadas, e que deverão concluir-se, assim como executar-se as outras, que possão ser uteis á instrucção dos Meus Vassalos, e extensão dos conhecimentos, de que tanto depende a sua felicidade ... (Portugal, 1801).

Os prefácios escritos por Veloso são motivados e influenciados pela posição do autor como cliente em uma relação de patronagem na qual o Príncipe Regente Dom João era o patrono final, com a mediação de Dom Coutinho. Essa ligação entre o autor/tradutor/ editor e o poder governamental também explica, por exemplo, a escolha dos temas e autores traduzidos. No entanto, apesar de esse vínculo necessariamente implicar a submissão aos interesses do sistema colonial português, as atividades desenvolvidas por Veloso, ainda que financiadas por tal sistema, levaram a resultados completamente opostos àqueles desejados pela coroa portuguesa. Entre esses resultados, estão: 
(i) o desenvolvimento de técnicas de impressão, em um sistema monárquico que se utilizava da censura a material impresso como estratégia de controle social;

(ii) a criação de um ponto de encontro para jovens intelectuais brasileiros na Arco do Cego, em uma atmosfera que possivelmente permitia debates e troca de ideias entre pessoas cuja atuação seria decisiva para a independência do Brasil anos depois; e

(iii) o avanço de ideias "perigosas" do Iluminismo em Portugal e no Brasil, já que mesmo textos científicos supostamente neutros estavam baseados na crença, na razão e no questionamento da autoridade.

Essas consequências inesperadas relacionam o trabalho de Veloso com o conhecido adágio traduttore, tradittore. Não se trata, porém, de uma noção da condição do tradutor como agente secundário da produção textual, alguém que não consegue lidar com o encontro entre línguas sem cometer crime de lesa-majestade contra o senhor texto original ou contra o autor desse texto soberano. Uma interpretação mais contemporânea e positiva desse status de traidor aponta para outra direção, que concorda com a visão de Lefevere de que os tradutores, enquanto reescritores, raras vezes podem escapar de cometer traições no seu trabalho com textos (1992, p. 13). Essa visão do tradutor como manipulador da situação de produção textual em que se encontra pode ser combinada com outros significados das palavras traição e traidor, como os registrados por Machado em seu Dicionário Etimológico de Língua Portuguesa (1995, v. V, p. 322):

Traição, s. Do lat. Traditīone, "o acto de entregar, de transmitir; entrega; rendição de cidade; transmissão, ensino; relação, narrativa, relatório". 
Traidor, adj. Do lat. Traditōre, "traidor; o que transmite, o que ensina”.

Como o maior e principal interesse de Veloso era disseminar conhecimento e educar, mesmo dentro dos parâmetros de uma política oficial portuguesa, ele parece um candidato forte para receber o título de traidor, adjetivo que tem também o sentido "o que ensina" ou seja, aquele que entrega o conhecimento a alguém que anteriormente não o possuía. Trata-se da revelação de segredos. No caso de Veloso e dos outros tradutores que com ele trabalharam, esses segredos estão ligados às novidades científicas e técnicas que ocorrem nos anos setecentos, e são segredos concretizados pelos/ nos textos estrangeiros que chegam a Portugal. A revelação ou traição, portanto, se dá em duas frentes: (i) a própria transmissão da ciência, permitindo a democratização do conhecimento e dos princípios racionais e experimentais do Iluminismo, e (ii) a rendição desse conhecimento na língua nacional, sem o mistério da língua estrangeira. Os textos traduzidos são as provas concretas da traição.

Sob uma perspectiva histórica, a entrega do conhecimento de que Veloso participa leva a consequências bem diferentes daquelas desejadas pelo poder imperial, preocupado basicamente em manter o Brasil como mero provedor de produtos agrícolas para o bem e para a riqueza do reino português. Em longo prazo, portanto, a traição do tradutor ocorre também em termos mais práticos, pois o interesse do patrono (ou seja, de quem pagou pela tradução) não foi alcançado. Portugal nunca recuperou sua posição dominante como potência mundial, que era a esperança subjacente ao projeto editorial de Veloso como um todo e a justificativa para o investimento feito pela coroa portuguesa. 


\section{Notas}

1. Diferentes grafias foram registradas para o sobrenome do Frei, tais como Veloso, Velozo, Velloso e Vellozo. A opção feita aqui foi pela versão Veloso, devido ao seu uso na publicação $A$ Casa Literária do Arco do Cego: bicentenário, obra comemorativa dos 200 anos de fundação da tipografia administrada por Veloso em Lisboa. No entanto, em citações de trabalhos de Veloso, a grafia utilizada será aquela registrada pelo autor ou editor.

2. Com relação ao trabalho com outras editoras lisboetas, ver Domingos, 1999.

3. Para uma lista completa dos tradutores que atuaram na Casa do Arco do Cego, ver Wyler: 2003, p. 89.

\section{Bibliografia}

CURTO, D. R. D. Rodrigo de Souza Coutinho e a Casa Literária do Arco do Cego. In: CAMPOS, M. F. (org.). A Casa Literária do Arco do Cego: bicentenário. Lisboa: Biblioteca Nacional e Imprensa Nacional, Casa da Moeda, 1999, p. 15-49.

CHARTIER, R. Poder y Escritura: El Príncipe, La Biblioteca Y La Dedicatoria (Siglos XV-XVII). Manuscrits, 14, 1996, p. 193-211.

DOMINGOS, M. D. Mecenato político e economia da edição nas oficinas do Arco do Cego. In: CAMPOS, M. F. (org.). A Casa Literária do Arco do Cego: bicentenário. Lisboa: Biblioteca Nacional e Imprensa Nacional, Casa da Moeda, 1999, p. 91-106.

FARIA, M. F. Da facilidade e da ornamentação: a imagem nas edições do Arco do Cego. In: CAMPOS, M. F. (org.). A Casa Literária do Arco do Cego: bicen- 
tenário. Lisboa: Biblioteca Nacional e Imprensa Nacional, Casa da Moeda, 1999, p. 107-137.

GAMA, A. B. Livreiros, editores e impressores em Lisboa no século XVIII. Arquivo de Bibliografia Portuguesa, Ano XIII, n. 49-52, Coimbra, 1967, p. 8-81.

LEFEVERE, A. Translation, rewriting, and the manipulation of literary fame. London/New York: Routledge, 1992.

MACHADO, J. P. Dicionário etimológico da língua portuguesa. Lisboa: Livros Horizonte, 1995.

MARTINO, A.; SAPATERRA, A. P. A censura no Brasil do século XVI ao século XIX. Estudos linguísticos, v. 15, 2006, p. 234-243. Disponível em: http://gel. org.br/4publica-estudos-2006/sistema06/169.pdf. Acesso em: 07 de out. 2009.

NUNES, M. F., BRIGOLA, J. C. José Mariano da Conceição Veloso (17421811): um frade no universo da natureza. In: CAMPOS, M. F. (org.). A Casa Literária do Arco do Cego: bicentenário. Lisboa: Biblioteca Nacional e Imprensa Nacional, Casa da Moeda, 1999, p. 51-75.

PORTUGAL. Decreto de 7 de dezembro de 1801. Disponível em http://www.iuslusitaniae.fcsh.unl.pt/verlivro.php?id parte $=110 \&$ id obra $=73 \&$ pagina $=1190$. Acesso em: 07 de out. 2009.

PRIORE, M. D.; VENÂNCIO, R. Uma história da vida rural no Brasil. Rio de Janeiro: Ediouro, 2006.

VELLOZO, J. M.C. Prefácio. In: O Fazendeiro do Brazil: cultivador, melhorado na economia rural dos generos já cultivados, e de outros que se podem introduzir; e nas fábricas, que lhe são proprias, segundo o melhor, que se tem escrito a este assumpto. Tomo I, Parte I (Da cultura das canas e da factura do assucar). Lisboa: Régia Officina Typographica, 1798.

VEllozo, J. M. C. Prefácio. In: BARBUT. J. Helminthologia Portuguesa, em que se descrevem alguns generos das duas primeiras ordens, intestinaes, $e$ molluscos da classe sexta do reino animal, vermes, e se exemplificão com varias 
amostras de suas especies, segundo o systema do Cavalheiro Carlos Linne. Lisboa: Officina de João Procópio Correa da Silva, 1799a.

VELLOZO, J. M. C. Prefácio. In O Fazendeiro do Brazil: cultivador, melhorado na economia rural dos generos já cultivados, e de outros que se podem introduzir; e nas fábricas, que lhe são proprias, segundo o melhor, que se tem escrito a este assumpto. Tomo I, Parte II (Da cultura das canas e da factura do assucar). Lisboa: Officina de Simão Thaddeo Ferreira, 1799b.

WEGNER, R. Livros do Arco do Cego no Brasil Colonial. História, Ciências, Saúde-Manguinhos, Rio de Janeiro, v. 11 (Suplemento: 1), 2004, p. 131-40. Disponível em: http://www.scielo.br/pdf/hcsm/v11s1/06.pdf. Acesso em: 07 out. 2009.

WYLER, L. Línguas, poetas e bacharéis: uma crônica da tradução no Brasil. Rio de Janeiro: Rocco, 2003. 